\title{
The Grammar of Measurement
}

\author{
Roger Schwarzschild \\ Rutgers University
}

\section{Partitives and Compounds}

The phrase 2 liters of oil is a pseudopartitive. It includes a measure phrase, 2 liters, and a substantive indicating what kind of substance is measured. I can use 2 liters of oil to talk about oil whose volume is 2 liters. Suppose I wanted instead to talk about oil whose temperature was 90 degrees. I should be able to say $* 90$ degrees of oil, but I can't. Instead, I have to say 90-degree oil. The absence of of indicates that this is not a pseudopartitive. The absence of number marking on degree suggests that it is a nominal compound. What is it about 90 degrees that prevents its use in pseudopartitives but allows it compounds?

too much gold is also a pseudopartitive, which, for reasons not relevant here, needs no of. Parsons(1970) observed that expressions like these are ambiguous about how the gold is being measured. It could be too much gold by weight or too much by volume. But if it can mean gold which is too heavy or gold whose volume is excessive, why can't it mean gold which is too dark? "You put too much gold in the ring," I would say to the jeweler, to mean that the gold in the ring is darker than I wanted. But I can't use too much gold in that way, and it isn't because much is unable to quantify over degrees of darkness, for that is just what it seems to do when I say "the gold is much darker than I had expected."

Inches and feet are appropriate units for measurements taken in various dimensions. Nevertheless, while I can use a foot of cable to speak of length, if I'm concerned with the diameter of the cable, why must I say quarter inch cable, again employing a compound, which is of-less and devoid of number marking, and where the indefinite article is omitted before quarter? And if 2 feet of cable concerns the length of the cable, how is it that 2 feet of snow tells us about the depth of the snow and nothing about the length?

Terminological Note. 'pseudopartitive' is a descriptive syntactic label, while 'measure phrase' and 'substantive' are semantic labels. I use 'measure phrase' to include not only noun phrases whose head is a term of measure such as gallon or ounce, but also adjectival phrases such as much, too much and so many as well as expressions such as a lot or a little or a truckload. 'substantive' is used to cover noun phrases like those following of in a pseudopartitive as well as the head nouns of compounds. Although both compounds and pseudopartitives do not have to be formed with measure phrases, until further notice, I restrict consideration to those that are. 


\section{Monotonic systems of measurement}

A system of measurement is one in which elements of an ordered set of measurements, a scale, are assigned to a domain of entities, based on some property. The goal is for the ordering of the measurements to reflect the degree to which entities in the domain have the property in question. Higher length measurements are assigned to longer objects, higher temperatures to hotter ones and so on. Now while all measurement systems mirror the degree to which an entity has the property in question, some but not all mirror as well the intuitive part structure of the stuff being measured. For example, if a quantity of oil has a certain volume, then every proper subpart of it will have a lower volume and superparts will have larger volumes. On the other hand, if the oil has a certain temperature, there is no reason to expect that proper parts of it will have lower temperatures. We will call a property monotonic if it tracks part-whole relations. Volume is monotonic and temperature is non-monotonic. Pseudopartitives may be based on monotonic properties such as volume of oil, hence 2 liters of oil is good but never on non-monotonic properties, hence $* 90$ degrees of oil is bad. Exactly the reverse is the case for compounds in English, for while the nonmonotonic 90 degree oil is felicitous, compounds cannot be formed when the interpretation is based on a monotonic property: *2 liter oil.

A monotonic property was just defined as one that tracks the part-whole structure of its domain, but which part-whole structure? To see the bite of this question consider a spool of computer cable. If we take its parts to be linear segments, then length is monotonic, but diameter is not, and we correctly predict that 2 feet of cable being a pseudopartitive would have to be interpreted in terms of length, not diameter, while $1 / 4$ inch cable, being a compound, would have to be interpreted in terms of diameter and not length. Things work out nicely if we suppose a part structure given in terms of linear segments. Assume instead that our parts include slices running the length of the spool or worse any portion of cable. Now the monotonicity facts change and we fail to explain our second set of puzzles.

The upshot of the previous paragraph is that pseudopartitives and compounds and, as we shall see, their cross-linguistic kin, all presuppose a particular part-whole structure for the stuff being measured. In the case of the pseudopartitive, the property which forms the basis for measurement has to be monotonic relative to the given part-whole structure, for compounds it needs to be non-monotonic. The choice of the part-whole structure will often be given by convention, as in the cable example. But we should also expect it to be sensitive to facts salient in the discourse. Witnessing a growing pool of oil seeping out of the ground, we may report its progress by declaring there to be 10 inches of oil, by which we intend to report that the pool has a radius of 10 inches. The relevant parts are concentric subpools and so in this case radius is monotonic for if $\mathrm{A}$ is a subpool of B, then A's radius is less than B's. This is a very specialized context. The limiting case, where context and convention make no contentful contribution, is where you have a complete mereology. That's what we had when we spoke of oil and gold. 
In 2 inches of snow, depth provides the basis for measurement. Given that 2 inches of snow is a pseudopartitive, we can reason backwards that the relevant part-whole structure is one that makes depth monotonic, one in which the proper parts are layers of snows. Since presumably this has to do with how we think about fallen snow, we should find the same situation with other snowy pseudopartitives. That is why when I say too much snow fell, I convey that the depth was excessive. Similarly, if two inches of snow fell on Florida and 10 inches of snow fell on Rhode Island, I can say that Rhode Island got more snow than Florida, even though the surface area and the mass of Florida snow exceeds that of Rhode Island. I've assumed, not without precedent (e.g. Jackendoff 1977), that too much snow and more snow than Florida got are pseudopartitives, despite the lack of of. Our gold puzzles support this hypothesis. Recall that too much gold allows for mass and volume interpretation, which are monotonic systems for gold, but not darkness. Darkness is non-monotonic since there is no guarantee that any subpart of a lump of gold will be less dark than the lump itself. Darkness is non-monotonic, so a pseudopartitive like too much gold cannot be based on that kind of measurement.

Krifka(1989) ${ }^{1}$ points out the contrast between five ounces of gold and *twenty carats of gold. The difference, he claimed, was due to the fact that ounce but not carat denotes an extensive measure function. He credits

Cartwright(1975) with the introduction of measure functions in the semantics of measure phrases. We'll have a bit more to say about this below. One of the requirements for extensivity is that the measure function be additive. If the band weighs 1 ounce and the diamond weighs $1 / 4$ of an ounce, then the ring weighs $1 \frac{1 / 4}{4}$ ounces. This doesn't work with carat ratings (n carat gold is $n$ 24ths pure gold). Lønning(1987) was concerned with "how much of mathematics should be part of the semantics" and so he considered concerned various alternatives to additivity, including what he called 'monotonicity'. A function that gives ounce measurements is monotonic in this sense because if $\mathbf{a}$ is part of $\mathbf{b}$ and $\mathbf{a}$ weighs $\mathbf{n}$ ounces and $\mathbf{b}$ weighs $\mathbf{m}$ ounces, then $\mathbf{n}$ is less than $\mathbf{m}$. I got the idea of monotonicity from Lønning, but I was concerned with how much of measurement practice should be part of this story, given that it would apply to adjectival measure phrases as well. For me, monotonicity is not a characteristic of the measurement system, but rather a characteristic of the property on which the system is based. Early discussions of measurement looked at monotonic properties as a basis for measurement and later this became a constraint on measurement schemes (Díez 1997).

\section{The Mass-Count Distinction}

The expressions considered so far all contain a measure phrase such as 2 feet, too much as well as a substantive. So far, we've taken the job of the substantive to name the kind of stuff that is measured. I'd like to suggest now that the choice of a particular part-whole relation is also settled in the course of interpreting the substantive This may seem at first unnatural, for surely the restriction to layers of 
snow or linear segments of cable has to do with how we conceive of fallen snow and our practices concerning cable and not anything to do with the English words snow and cable. But the motivation for this move comes not from these examples, but from an examination of the differential behavior of mass and count nouns in pseudopartitives and compounds. While we can say 2 hours of work and 2 pages of prose, if we replace the mass nouns with related count nouns we arrive at the impossible pseudopartitives $* 2$ hours of job and *2 pages of story. These contrast with the corresponding compounds which are good: a 2 hour job, $a 2$ page story. Likewise, it is rude to announce the birth of 7 pounds of baby but $a$ 7pound baby is perfectly welcome.

Since the difference between a count and a mass noun is commonly taken to be a reflection of the salient part-whole relation, it seems worthwhile to try to account for these facts in terms of monotonicity. The leading idea would be that the extensions of singular count nouns are atomic, they fail to offer anything but a trivial part-whole relation. Monotonicity fails in these cases because it requires a part-whole relation to work off of. Pseudopartitives require monotonicity, so they fail with count nouns, while compounds abhor monotonicity and so they succeed with count nouns.

The restrictions discussed in the previous section can now be elaborated as follows. A pseudopartitive may be interpreted in terms of a measurement system if the denotation of the substantive comes with a part whole relation and the basis for the measurement is monotonic within the universe of the substantive with respect to its part-whole relation. Compounds require that these conditions not obtain, either because the substantive doesn't come with a part whole relation or because it does come with one but the measurement system is not monotonic within the universe of the substantive with respect to the part-whole relation.

This statement presupposes that noun extensions are potentially structured objects, with a universe of elements and a part-whole relation. For singular count nouns there is no part-whole relation, but for mass nouns there is. Furthermore, the universe and the part whole relation is partially pragmatically determined. In other words, when discussing fallen snow, the extension of snow just is a set of more or less continuous layers of snow. On the standard account, by contrast, the extension of snow includes all the bits of snow and the part-whole relation is just material-part. Let's assume then that context can narrow down the standard extension in such a way that no material is lost (the sum of all elements in the universe of the restricted structure is the same as in the unrestricted structure) and no new individual part-whole relations are added (if $\mathbf{a}$ is part of $\mathbf{b}$ in the restricted structure, $\mathbf{a}$ is part of $\mathbf{b}$ in the unrestricted one).

Given that singular count nouns never provide a non-trivial part-whole relation, they will always be bad in pseudopartitives and they will always be good in compounds. In fact, they will be good in compounds even when a corresponding mass noun is not. This leads to the following contrasts:
*2 hour work
2 hour job
*2 liter oil
2 liter tank
*2 lb flour
$2 \mathrm{lb}$ rock 
In each of these cases, the mass version is impossible because the basis for the measurement (duration, volume, weight, or page count) is monotonic on the partwhole relation. The count versions are possible, because the part-structure makes these same properties non-monotonic on the atomic part-structure associated with count nouns. In a sense, it's the measure phrase that explains why $20^{\circ}$ salt water is possible while it's the noun that explains why $2 \mathrm{lb}$ rock is.

Again following standard practice, we take plural nouns as coming with a part-whole structure given by the plural-part relation (the relation I bear to the plurality consisting of you and me). This means that they should behave more like mass nouns than like their singular counterparts. This is borne out in the case of pseudopartitives. 2 kilos of marbles contrasts with *10 degrees of ice cubes. But how do we explain the grammaticality of 7-pound babies given that *7-pound flour is out? The answer is that in 7-pound babies the plural marker has scope over the entire compound, in effect we have pluralized 7-pound baby. The interpretation is indeed one in which each baby weighs 7 pounds.

A predicative definite noun phrase never is true of more than one entity. In that case, the part-whole structure of its extension would have to be atomic, like that of a singular count noun and so we should not expect to find a definite noun phrase functioning as a substantive in a pseudopartitive. How then can we explain things like 4 pounds of the oranges or 2 pages of the first story? These are examples of true partitives which at least since Selkirk(1977) have been distinguished syntactically from pseudopartitives. Below we will take up some of the syntactic details, for now it should suffice to use the behavior of of to argue for the distinction. While pseudopartitive of does not occur with adjectival measure phrases (too much gold), true partitive of is not so fickle (too much of the gold). In recipe English, the difference is seen with nominal measure phrases as well. There we find $2 \mathrm{lbs}$ butter but not $* 2 \mathrm{lbs}$ the butter. And if one ventures outside of English (and Romance) one finds the difference with nominal measure phrases more robustly. Dutch, for example, distinguishes een kilo appels 'a kilo of apples' from een kilo van deze appels 'a kilo of these apples'.

According to Ladusaw(1982), the true partitive of is meaningful. It combines with a definite noun phrase to form a predicate true of the parts of the referent of the noun phrase. Rephrasing slightly, the meaning of partitive of applies to the meaning of a definite noun phrase to deliver a universe consisting of the parts of the referent and the part-whole relation. Taking this unit to be our substantive, we now find contrasts like the ones we saw with the pseudopartitive: 2 ounces of the salt water versus ${ }^{*} 2^{\circ}$ of the saltwater; 2 minutes of the strenuous exercises versus $* 4 o^{\prime}$ 'clock of the exercises. On this way of thinking, our monotonicity constraints apply to all partitives, true and pseudo alike. The substantive in a pseudopartitive is a just a noun phrase, and it's extension must include a part-whole relation relative to which the basis for measurement is monotonic. The substantive in a true partitive consists of true-partitive-of combined with a definite noun phrase ${ }^{2}$. The extension of this combination 
includes a part-whole relation relative to which the basis for measurement is monotonic.

Let's take stock. Measure phrases combine with nouns in two different ways in English. In either case, the interpretation relies on some property that elements in the extension of the noun possess to varying degrees and in virtue of which a measurement can be made, a measurement whose result is described by the measure phrase. This property, the basis for measurement, must obey opposing restrictions in the two constructions. In one case, partitives, it must be monotonic relative to the part-whole structure given by the meaning of the noun it combines with, in the other case it must not be monotonic. This has a number of consequences including the following. Measure phrases from the realm of temperature combine with nouns in the compound-mode, but not in the partitivemode. Measure phrases from the realm of volume combine with mass nouns in the partitive-mode, but not in the compound-mode. Count nouns offer no partwhole relation, hence they are always allowed in a compound and absent the intervention of a true partitive of they are always excluded from the partitive. Finally, if plurals are used, the measure phrase will apply distributively in the compound (6 ounce pebbles), but collectively in the partitive (6 ounces of pebbles).

Ultimately, it would be nice to know where these monotonicity restrictions come from and how they relate to the syntax of these constructions. In the following two sections, we will elaborate on the interpretation of measure phrases and the syntax of partitives. Following that we will offer some ideas about the place of monotonicity in the grammar.

\section{Measure Phrases}

As Jackendoff(1977) pointed out, measure phrases have a wide distribution. Degree phrases and prepositional phrases are just two contexts outside the ones we've considered so far in which measure phrases appear:

(2) $\$ 2$ more expensive, 2 lbs too heavy

2 feet away, $2^{\circ}$ below, $\$ 2$ over that much faster, much too spicy

that much above the house

This pattern of distribution is by no means peculiar to English. It occurs in such diverse languages as Bangla (Bhattacharya 1999), Hebrew, Hindi, Japanese and Polish. A possible explanation for why measure phrases are crosscategorial is that they have a uniform semantics and that the meaning in question happens to be called for in various contexts. This is a fairly pedestrian idea nevertheless it is one that I think has not yet been pursued and which seems worthy of consideration. I will attempt this beginning with a semantics of measure phrases worked out for the comparative. A reason to choose the comparative as the starting point is that of the various contexts where measure phrases are possible, the comparative is the least restricted. Note, for example, that while the availability of a measure phrase in the partitive is constrained by 
monotonicity, the comparative has no such restriction. I do not yet know whether the comparative is in fact the least marked context for measure phrases, from an historical and a typological perspective.

In Schwarzschild and Wilkinson(2002), ${ }^{3}$ we analyzed measure phrases in comparatives as predicates of parts of scales. To fix on an image, think of uses of expressions like 2 inches to talk about intervals of a ruler:

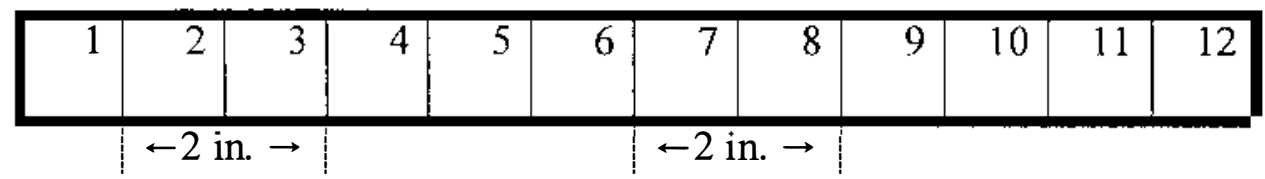

The idea is to draw an analogy with adverbs of duration. The following examples illustrate the analogy.

(3) He shot the sheriff [2 hours] before he shot the deputy.

(4) $\operatorname{Rod} A$ is $[2$ inches] longer than $\operatorname{rod} B$ is.

In (3), 2 hours is predicated of the interval on the time line between the two shootings. In (4), 2 inches is predicated of the interval on the scale between where $B$ is and where $A$ is. This view extends to adjectival measure phrases as well. In (5) below:

$\operatorname{Rod} \mathrm{A}$ is [much] longer than $\operatorname{rod} \mathrm{B}$ is.

much tells us that the size of the interval on the scale between where B is and where A is is large. On this view, much has a semantics quite like that of long. Both adjectives apply to extended entities, with much restricted to abstract, scale parts. Since both are gradable, we find too long, so long, that long alongside of too much, so much, that much. And in both cases, when no degree word such as too or that is present, one gets a 'higher than expected' reading. So if the diamond were that much heavier contrasts with if the diamond were much heavier in the same way as if the necklace were that long contrasts with if the necklace were long.

This view of measure phrases is based on the semantics for comparatives. Zwarts(1997) independently came to a very similar conclusion about measure phrases in his analysis of the semantics of prepositions. My hypothesis that measure phrases have a uniform semantics amounts now to the claim that, regardless of its external or internal syntax,

(6) a measure phrase just is a predicate of scalar intervals.

Jackendoff(1977) and Klooster(1972:18ff) observed that the quantifier in a nominal measure phrase has to be weak. We cannot say *most feet taller, *most feet of yarn, *ran most miles or *most inches above the painting. This restriction follows from (6) and the general prohibition on strong quantifiers in predicative noun phrases. 
Adger(1994) notes that the ban on strong quantifiers extends to arguments of measure verbs (*weighs most ounces). Adger discusses a number of other properties of the objects of measure verbs which lend further support to the idea that they are predicative. These include Rizzi(1990)'s observation that measure phrase arguments are sensitive to weak islands (What don't you think he saw? versus What don't you think he weighs?); the failure of measure phrases to passivize (*2 ounces was weighed by it); Smith(1992)'s observation that measure phrases don't show past participle agreement in French (Les vingt grammes que cette lettre a pesé(*es) 'the twenty grams that this letter has weighed') and finally Adger's own observation that in languages like Turkish, measure phrase arguments do not undergo specificity-sensitive scrambling.

If measure phrases are predicates of scalar intervals and noun phrases are not in general predicates of or quantifiers over scalar intervals, then we will need some help to put them together in the interpretation of a partitive or compound. Roughly following Parsons(1970) and Higginbotham(1994), we will make use of functions which map entities to intervals of a scale. The intention is to understand three ounces of gold disappeared along the lines of (7) below ${ }^{4}$ :

$$
\exists x[\operatorname{gold}(x) \& \text { disappeared(x) \& three-ounces(wt.(x))] }
$$

Here wt. is a function that applies to objects with weight and returns an interval that begins at the bottom of the scale and whose length depends on the weight of the object in question. Different partitives will require different functions from entities to intervals. The interpretation of 2 hours of work requires, for example, a function assigning intervals on a scale of durations. The choice of function will be constrained by the meanings of the measure phrase and the noun phrase but it won't always be determined by them. The interpretation of $2 \mathrm{ft}$ of snow normally relies on a depth function, however, if, by chance, we are discussing a line of snow that someone has laid to create a boundary, then we make use of a length function to interpret He has already laid down $2 \mathrm{ft}$ of snow.

I should briefly note here that, like Nerbonne(1995) and Krifka(1989), I imagine the analysis of measure phrases to extend to numerals. The interpretation of 9 boys makes use of a function from pluralities to intervals on a cardinality scale and 9 is a predicate of such intervals. Expressions like 9 more bottles, 9 too many point to the inclusion of numerals in the class of measure phrases (and similar observations lead to the idea that numeral-classifier combinations are measure phrases, see Kikuchi 2001 for relevant data). Likewise, many more boys suggests that many be treated like much with the added requirement that it apply exclusively to intervals of scales of cardinality or proportions.

At this point, we have proposals for the meanings of the parts of a partitive. The next task is to investigate how partitives are constructed. Before turning to that task, I want to briefly address a popular alternative to our semantics for measure phrases. Quine(1960:244-5) absurdly interrogates "Are miles alike? If so, how can they count as many? And if they cannot, what of the two hundred between Boston and New York?". He advises to replace "length of Manhattan $=11$ miles" with a Carnapian "length-in-miles of Manhattan $=11$ " . 
This maneuver is applied to partitives by Krifka(1989), Higginbotham(1994) and Chierchia(1998:74) where sentences such as 6 oz. of salt melted are analyzed along the lines of:

$$
\exists y[\operatorname{salt}(y) \& \operatorname{melted}(y) \& \operatorname{oz}(y)=6 .]
$$

Nobody, as far as I know, has explained how this view is supposed to connect with the semantics of expressions like $6 \mathrm{oz}$. heavier or 6 oz over the limit. ${ }^{5}$ Adjectival measure phrases present another problem for they do not correspond to a particular scheme of measurement and they do not take numeral arguments. Even nominal measure terms can get by without numeral arguments (several ounces of salt). One could try to analyze these examples in terms of quantification over numbers. several might, for example, existentially quantify over numbers of a certain size. But that idea conflicts with what one finds when these quantifiers are inserted into contexts that clearly call for numerical arguments:

(9) *Four plus several is less than 10. "there is a number greater than 2: 4 plus that number is less than $10 . "$

* My three-year-old can count up to several.

*There were exactly several groundhogs.

\# "for some $\mathrm{n}$ greater than 2 : there were exactly n groundhogs"

Finally, it is hard to explain the choice of plural ounces in the expression ten ounces of salt on the assumption that ten is a number-denoting argument of ounces (compare ten is greater than six). On the theory proposed here, the extension of ounces includes pluralities, each of which consists of at least two intervals in the extension of ounce. ten ounces is interpreted with a cardinality function, just like 9 boys.

\section{Extended Projections of N: Pseudo and True Partitives.}

Giusti(1997) posits two distinct positions where quantifiers such as Italian tutti 'all' and molti 'many' may be generated. The positions differ in terms of their order relative to determiners. These are depicted in the trees below:

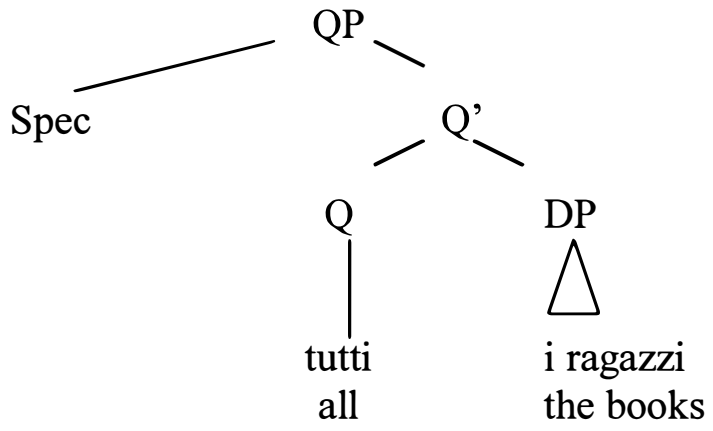


(13)

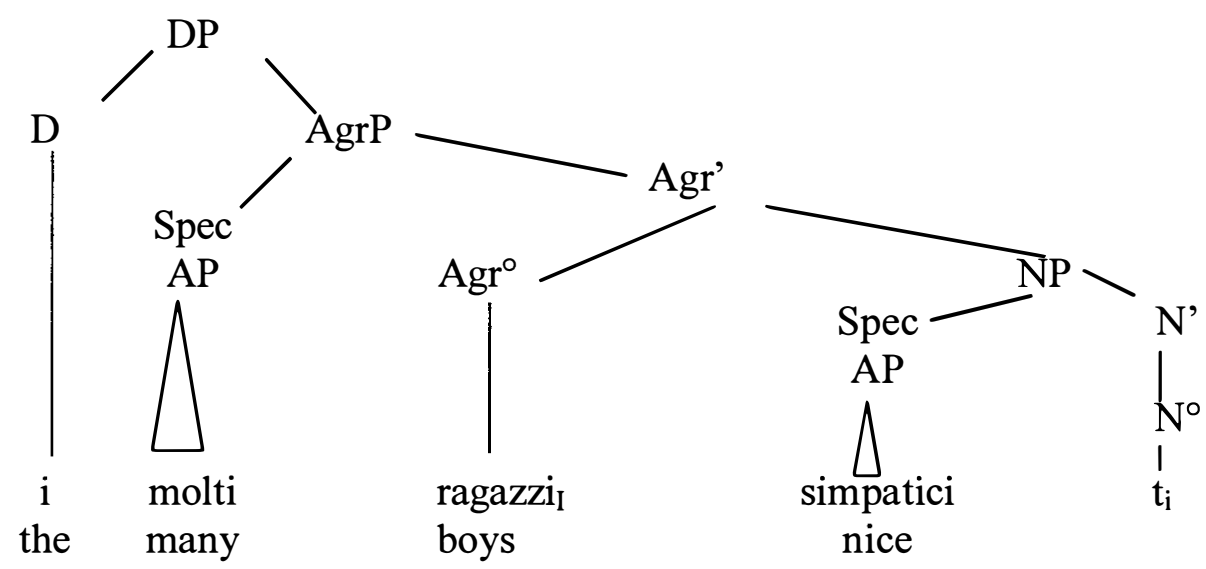

Giusti observes that the two quantifier positions differ with respect to whether they permit the extraction of a pronoun:

(14) ho visto molti ragazzi.

I.have seen many boys

(15) $\mathrm{ne}_{\mathrm{i}} \quad$ ho visti molti $\mathrm{t}_{\mathrm{i}}$

of.them I.have seen many

(16) ho visto i molti ragazzi.

(17) $*$ ne $_{\mathrm{i}}$ ho visti i molti $t_{\mathrm{i}}$

With the analyses in (12)-(13), we explain this difference simply by taking $n e$ to be a DP.

In the tree in (13), Giusti follows the general program of Cinque(1994) in which adjectives are inserted in the specifier of a nominal functional projection. In those positions they agree with the noun through Specifier-Head agreement. Both simpatici and molti are masculine plural indicating that all functional heads bear the number and gender features of the projection. Now in (12), tutti similarly agrees with the head noun. Giusti(1997) argues that quantifiers are not functional, which means that in (12) we have an odd case of a lexical head agreeing with its complement. Moreover, as Delsing(1993) points out, this kind of approach means that categories selecting noun phrases would have to specify QP or DP or both. This suggests to me that we replace (12) with a structure in which $\mathrm{Q}$ is a functional head with tutti in its Specifier ${ }^{6}$. 


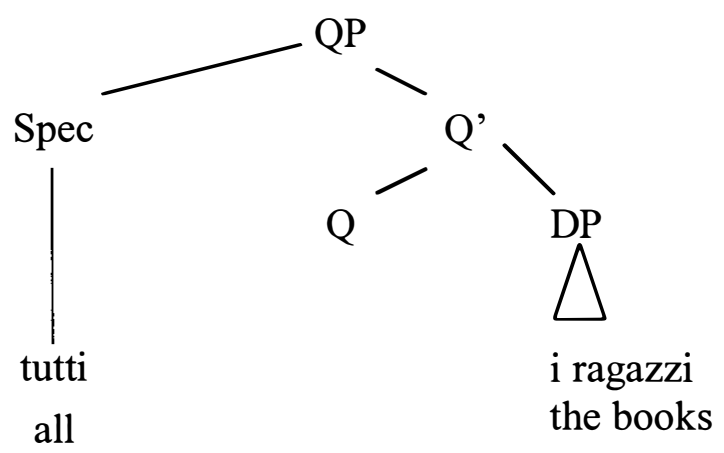

With (18), we can now accommodate further cases. too much of the rice is generated with the phrasal too much in Spec,QP and the DP the rice in the complement of Q. Assuming that possessives are generated in Spec,DP (see Giusti 1997 and references therein), Jackendoff(1977:124)'s pair below follows immediately:

(19) *John's many of those objections. John's many objections.

many must be in Spec,AgrP in these examples, since it follows the possessive and hence is within a DP. This means we have a structure like in (13). In that case, there is no room for a DP to follow many, hence the ungrammaticality of (19).

Turning to nominal measure phrases, simplicity demands that we take them to fill these very same specifier positions. They too appear before and after determiners:

(21) What will I do with 2-lbs of the cottage cheese?

(22) What will I do with the 2-lbs of cottage cheese?

Recall that ne cliticization was taken to be diagnostic for the presence of a DP inside a QP. Assuming that nominal measure phrases occupy Spec,QP leads to the correct prediction that they too licence this type of cliticization. Proudf oot and Cardo teach that when the shopkeeper asks if you want some of the bread, you can reply:

$$
\begin{aligned}
& \text { si, ne } \left.\left.\left.\quad \mathrm{ne}_{\mathrm{i}} \text { vorrei [QP [un chilo] [Q' [DP } \mathrm{t}_{\mathrm{i}}\right]\right]\right] \\
& \text { yes, CL-gen I-would-like a kilo }
\end{aligned}
$$

By way of summary, let us distill out the crucial claims. There are at least three functional levels in the projection of a nominal: Q(uantity), Agr(eement) and $\mathrm{D}$ (eterminer). Quantifiers or measure phrases can at least be Specifiers of QP and AgrP. Following the logic of Grimshaw(1991,2000), we further stipulate that AgrP may not dominate DP or QP and that DP may not dominate QP. This is perhaps all that needs to be said. Giusti further stipulates selectional requirements 
for various quantifiers, but this may not be necessary. This setup allows that quantifiers in QP may combine with DPs, but they may also combine with AgrPs or NPs. In section 3, we deduced from monotonicity requirements that measure phrases in partitives could combine either with NPs or with definite DPs when a partitive-of is present. A full treatment of all is beyond the bounds of this paper. However, assuming Brisson(1998)'s semantics, we capture the contrast between all the boys and *the all boys (for more discussion along these lines, including expressions such as all men, see Matthewson(2001), Zamparelli(1996)).

We close this section with some speculations on of. Suppose that of may be inserted in the head of a functional projection. In 2 ounces of salt, it shows up in the head of QP, while in the 2 ounces of salt, it fills the head of AgrP. In the first case, the measure phrase 2 ounces is the Specifier of QP. As such, it is meant to agree with the head Q. But the measure phrase itself is headed by a noun. Assuming that agreement is an asymmetric relation - one party is agreeable and the other demands agreement - then we have a problem. The measure phrase is being asked to agree, when it is a trigger for agreement. In this case then, of is a disagreement marker which steps in to solve this problem ${ }^{7}$. This is only necessary when the head of the measure phrase is nominal. No problem arises when it's an adjective (Gawron 2002). This hypothesis covers not only things like 2 ounces of versus too much *of, but it also covers idiomatic measure phrases that use an indefinite article:
MP w/adj head
a little (*of) soap
a few $(*$ of) men
MP w/noun head
a bit *(of) soap
a number $*(o f)$ men

On this view, the optionality of of in all (of) the boys might stem from uncertainty about the categorial status of all. Unlike nouns, it cannot be pluralized. Unlike most adjectives, it does not take degree modifiers (*too all). I'm assuming that of is pseudopartitive in these cases. Brisson and Matthewson argue that the optionality itself shows that of is not a semantically necessary partitive marker. And both authors provide a semantics for all from which it follows that this of is vacuous. Furthermore, Hebrew, which is one of those languages that has a distinct true partitive preposition, does not employ it in this case $\left(^{*}\right.$ kol me-hayeladim 'all PART-the-child.MascPlural versus kol ha-yeladim 'all thechild.MascPlural').

If the pseudopartitive of adjudicates between competing agreement triggers, one might wonder what happens in languages without a pseudopartitive of. One alternative is to simply omit number marking on the measure term, as in the following German example:
zwei Pfund/*Pfunde Salz
[from $\operatorname{Vos}(1999: 52)]$
two pound/pounds salt
'two pounds of salt'

The preceding account could be extended to true partitive of but it needn't be. Jane Grimshaw (pc) suggested taking PP to form a layer of the extended 
nominal projection below QP but above DP (see Grimshaw 1991,2000 for arguments that PPs are extended nominal projections.). Under this view, true partitive QPs might be formed with true prepositions:

$$
\left[\mathrm{QP} \text { many }\left[\mathrm{Q}^{\prime}\left[\mathrm{Q}^{\circ}\right][\mathrm{PP}[\mathrm{of}][\mathrm{DP} \text { the trees }]]\right]\right]
$$

\section{The Grammar of (Non) Monotonicity}

We now have some idea of the syntax of partitives and it remains to combine this with what we know about the semantics of the parts. In section 4, we attributed to (26) the interpretation in (27)

$$
\text { three ounces of gold disappeared. }
$$

$$
\exists x[\operatorname{gold}(\mathrm{x}) \& \text { disappeared(x) \& three-ounces(wt.(x))] }
$$

In (27), 'gold' comes from the NP inside the QP in (26) and 'three-ounces' comes from the specifier of that QP. We have not yet said where wt comes from.

Recall that wt denotes a function from the extension of the NP to intervals on a weight scale. Different partitives make use of different such functions. We'll call these 'scale-functions' and we will use the variable $\mu$ to range over them. There are at least three possible loci for the scale function. It could be grafted on to the meaning of the measure phrase, it could be the meaning of a morpheme inserted between the measure phrase and the noun phrase or it may be part of the meaning of the NP. In expressions like 2 days worth of work, worth sounds like a scalefunction. For less common measure phrases it is even required for the formation of a partitive: 2 cappucinos later versus 2 cappucinos *(worth) of conversation. The proper analysis of the syntax of worth might help choose between the first two alternatives (does it share the $\mathrm{Q}^{\circ}$ node with of? Where is the genitive coming from in a week's worth of gas? What is elided in I want 2 dollars worth?). The third option, to include the scale function in the noun is actually suggested in Abney(1989). In section 2 of this paper, we argued that mass noun meanings come with a part-whole relation. It is a small step then to include a scale-function monotonic on that relation. It is unclear at this stage which of these three options is best. For concreteness, I will assume the first option, whereby the meaning of the measure phrase is augmented with a scale function ${ }^{8}$ :

$$
\text { MON } \quad \mathbf{m p} \rightarrow \lambda X \lambda z[X(z) \& \operatorname{mp}(\mu(z)) \& \quad \mu \text { is monotonic on } X .]
$$

Wherever the scale function goes in the partitive, it has to be monotonic, because it reflects the property on which the measurement is based. By calling the scalefunction monotonic, we mean that the values it assigns should increase as you ascend the part-whole structure of the NP extension and likewise they should decrease as you descend. Adopting the view that the scale function becomes part of the measure phrase now amounts to a substantive claim about how syntax 
constrains semantics. It says that if a measure phrase is inserted in a specifier of an extended nominal projection, it must be augmented with a monotonic scale function.

What does this mean for the measure phrase compounds discussed earlier ( 2 ounce saltshaker)? Here too presumably a scale function mediates between the noun and the measure phrase. But in this case, the scale function is required to be non-monotonic. And this requirement cannot simply be explained by the fact that the measure phrase is not in the specifier of an extended nominal projection. That fact only guarantees that the scale function is not required to be monotonic, but we need something stronger. Remember, we want to rule out $* 2$ oz salt because weight is monotonic relative to the saline mereology. Merely saying that monotonicity is not required will not do the trick. We need to say that monotonicity is prohibited, and we're looking for a formal hook to hang the prohibition on. The English facts presented so far might tempt one to look for an explanation in the difference between syntactic and morphological composition. A brief foray across linguistic boundaries will help us guard against this temptation. Although noun-noun compounds are possible in Spanish (hombres rana 'frog men' perro policia 'police dog' paises satelite 'satellite countries') they are not where you find non-monotonic uses of measure phrases. Instead what you find is verbally similar to the partitive but with the order reversed:

\begin{tabular}{|c|c|c|}
\hline \multirow[t]{5}{*}{ Spanish } & $\begin{array}{l}\text { Monotonic } \\
\text { dos centimetros de cable }\end{array}$ & $\begin{array}{l}\text { Non-Monotonic } \\
\text { agua de dos grados }\end{array}$ \\
\hline & $2 \mathrm{~cm} . \quad$ de cable & water 2 \\
\hline & ' 2 centimeters of cable (length)' & "2० water" \\
\hline & *dos grados de agua & *agua de dos litros \\
\hline & * 2 degrees of water & 2 liters \\
\hline
\end{tabular}

This alternative to compounds occurs outside Romance as well:

$\begin{array}{lll} & \text { Monotonic } & \text { Non-Monotonic } \\ \text { Dutch } & \text { een centimeter staaldraad } & \text { staaldraad van een centimeter } \\ \text { one cm. wire' } & \text { wire van one cm. } \\ \text { ' } 1 \mathrm{~cm} \text {. of wire' (length) } & \text { ' } 1 \mathrm{~cm} \text {. wire' (diameter) }\end{array}$

And it is probably what you have in the English a group of three men meaning 'a three man group'. There is another strategy found in German and Russian, whereby the measure phrase receives an adjectival suffix:

\section{Monotonic}

Swiss German foif liter wasser

5 liters water
Non-Monotonic

foifgredigs wasser

5 degree Adj water ' $5^{\circ}$ water' 
*foif graad wasser

*5 degree water

Russian

desiat' santimetrov vody
$10 \quad \mathrm{~cm}$. pl water-gen
'10 cm water'
*desiat' gradusov vody
$* 10^{\circ}$ of water

$*_{\text {foifliterigs wasser }}$

* 5 liter Adj water

desiatigradusnaja voda

10-degree-Adj water

" $10^{\circ}$ water"

*desiatisantimetrovaja voda

10-cm-Adj water

“* $10 \mathrm{~cm}$ water"

Suppose that in all these constructions a measure phrase is transformed into an adjective or perhaps some more general category like 'attributive'. The generalization then is that attributives are required to be non-monotonic. That would mean that the transformation that measure phrases undergo in these cases carries with it the following kind of semantics:

$$
\text { NONMON } \quad \mathbf{m p} \rightarrow \lambda X \lambda z[X(z) \& \mathbf{m p}(\mu(z)) \& \mu \text { not monotonic on } X .]
$$

If the non-monotonicity requirement is really tied to the category of adjective or 'attributive', we should detect it in constructions that lack measure phrases. An obvious place to look for such effects is in the semantics of adjectives that have meanings related to the measure phrases we've been looking at. What you find, in fact, is a pattern very similar to what we found with measure phrase compounds. Before looking at those facts, let us quickly remind ourselves of a few of the compound facts. $* 20$ oz water is out because weight is monotonic with respect to water-parts. 20 oz ice-cube works because count nouns come with no part structure, they in effect insure the absence of monotonicity. $20^{\circ}$ water is possible, because even though it uses a mass noun, temperature is not monotonic on water parts. 20 oz ice-cubes is possible, but only on a distributive reading where it is a plural of $20 \mathrm{oz}$ ice-cube. It is impossible to have the collective reading of $20 \mathrm{oz}$ ice-cubes where we get the weight of the plurality, because weight is monotonic on plural parts of the ice-cube plurality. Finally, in 1 inch cable, we get a measure of diameter, not length, because diameter is not monotonic on the most salient part structure of cable, one in which you have linear segments. We turn now to some examples in which you have adjectives combining with nouns in place of measure phrases. First, we contrast count and mass nouns. If I melt a heavy, carcinogenic ice-cube, I'm likely to get carcinogenic water, but I won't get heavy water. That's because the basis for determining heaviness is weight, and that is monotonic on water parts. For the same reason, I won't get light water either. ${ }^{9}$ This matters for the mass noun water, but not for the count noun ice cube. Similarly, if John has a large, parched lawn, he has parched grass, but not large grass. And if Jack ate long, sweet carrots for lunch, he's eaten sweet food, but not long food. Compare now the expressions cheap wine and cold wine. One way to describe the contrast is that cheap refers to the kind, while cold refers to the stuff itself. But there is another explanation. Temperature is non-monotonic, hence it 
works fine as the basis for an adjective applying to wine. Price, on the other hand, tends to be monotonic. The more you drink, the more you pay! But there is another monetary function lurking there. It is the one that applies to some stuff and gives you the price per unit of that stuff (the word price is really itself ambiguous). It is that scale function that is being used to determine the cheapness of the wine and that function is not monotonic. From the felicity of 2 inches of snow, we determined that talk of falling snow implies a part-whole structure in terms of layers. That explains the oddness of saying that deep snow fell on Rhode Island last night. And it is the linear-segmental structure of cable that explains why I can use thick cable to connect my computers but not long cable. When adjectives combine with plural nouns they can in principle have distributive or collective readings. If Jack told inconsistent stories, it could either be because the stories conflicted with one another (collective), or because each story contained an inner contradiction (distributive). But this ambiguity is lost in the phrase heavy ice-cubes which needs to be distributive for the same reason that 20 oz ice-cubes had to be. ${ }^{10}$

This little demonstration that attributive modifiers, not just measure phrase modifiers, have to be non-monotonic has some immediate consequences for the account we're working towards. First, it means that non-monotonicity isn't likely to be spelled out in terms of a requirement that a rule like that in (29) apply, unless it turns out that scalar adjectives are also predicates of intervals which get augmented with a scale-function. The second consequence concerns the syntaxsemantics mapping. If we return to Giusti's tree in (13), we find that the adjective simpatici is located in Spec,NP. Supposing that adjectives like heavy and cheap go there as well, we need to sharpen our earlier claim to the effect that specifiers in extended nominal projections are linked to monotonicity. Rather, specifiers in the upper reaches of an extended nominal projection require monotonicity, while those lower down requires its absence.

\section{Conclusion}

Loudness, pungency, intensity, temperature, weight and volume all name properties that can be had in varying degrees. These properties can be divided into two classes. There are some, like weight, whose degree is a reflection of amount. And there are others like temperature whose degree is not a good gauge of amount. We called the former monotonic, because their degree is monotonic on the part-whole relation. The latter are called non-monotonic. This distinction is linguistically relevant. Languages have various constructions where measure phrases and scalar adjectives combine with nominal expressions. Some of these constructions, the 'monotonic' ones, permit only combinations that reflect amount and some, the 'non-monotonic' ones, permit only combinations that don't reflect amount.

Mass nouns and plural nouns denote structured sets. The structure is given by a part-whole relation. Depending on the linguistic context, the relation may be as general as material-part or as specific as sublayer-of-snow. Count 
nouns denote unstructured, 'atomic' sets. This matters for monotonicity. The particular relation encoded in the noun will be the one relative to which the property in question needs to be or not be monotonic.

Measure phrases occur in various syntactic contexts. They denote predicates of scalar intervals. two ounces applies to intervals that are twice the size of those that one ounce applies to. When measure phrases combine with nominals, they are augmented with a function whose range is scalar intervals. The choice of function is constrained by whether the context is monotonic or nonmonotonic.

Measure phrases may inhabit specifier positions in the upper levels of nominal projections. When they do, they must be monotonic.

Attributive modifiers must be non-monotonic. These include adjectives as well as certain uses of measure phrases which include being the left member of a nominal compound, following of and its cognates and being a denominalized adjective. Attributive modifiers may inhabit specifier positions in the lower levels of nominal projections.

\section{Endnotes}

* The research reported here began in a most enjoyable seminar at Rutgers in Spring 2001. I'm grateful for the feedback I received there and from audiences at Rutgers(SURGE), SALT XII, USC, UCLA, UConn, UPenn and Utrecht University ("Acquisition Perspectives on Interfaces" conference). I would also like to express my gratitude to the following individuals: Ivano Caponigro, Mark Gawron, Jane Grimshaw, Bob Matthews, Cécile Meier, Kimiko Nakanishi, Ken Safir, Barry Schein and Karina Wilkinson. Finally, I thank the following linguists for native speaker judgments: José Camacho, Veneeta Dayal, Yoko Futagi, Bart Hollebrandse, Sophia Malamud, Sveta McCoy, Cécile Meier, Kimiko Nakanishi, and Bożena Rozwadowska.

${ }^{1}$ I am grateful to Peter Lasersohn for urging me to take a look at Krifka(1989).

2 Actually, as Barker(1998) notes, what is required is a noun phrase that denotes a proper principal ultrafilter. This includes definites as well as singleton indefinites.

${ }^{3}$ In that paper we argue for an analysis of comparatives based on intervals rather than points on a scale, in analogy with the move from moments to intervals in tense semantics. The theory there was chiefly motivated by examples in which quantifiers appear in comparative than clauses as in Irving was closer to me than he was to most of the others. The crucial intuition is that there may not be some particular distance such that most of the others are that distance away from me, but there is a range such that the distance from me to most of the others lies in that range.

${ }^{4}$ Parsons analysis for most gold is unmined in addition makes use of maximization. Extending that idea to the present case, (7) should be replaced with (i) below, where I've used a totalizing operator, $\Sigma$, (=Higginbotham(1994)'s 
nominalizer). (i) is to be read "the weight of the total amount of gold that disappeared is 3 ounces".

\section{i. 3 ounces $\left(\right.$ wt $\left(\sum X(\operatorname{gold}(X) \&\right.$ disappeared $\left.(X))\right)$}

This added sophistication is not relevant to anything that I have said or will say here. Maximization is acutely necessary, when considering paucal measure phrases (few, little, a bit).

${ }^{5}$ Lønning(1987:41) raises a related problem when he compares less than two kilos of cheese disappeared with the cheese that disappeared weighed less than two kilos. His proposal involves separating out two functions, one from objects to their weights and another that maps from weights to numbers. The first function is similar to our wt in (7).

${ }^{6}$ Giusti(91,97) was apparently led to the head analysis of all by Shlonsky(1991)'s account of the following pair of expressions from Hebrew, both of which mean 'all the books':
i. $[\mathrm{QP}[\mathrm{Q},[\mathrm{Q}$ kol $][\mathrm{DP}$ ha-sefarim $]]$
ii. [QP ha-sfarim ${ }_{i}\left[Q, k u l-a m t_{i}\right]$ ] all the-book.Masc.Pl
the-book.Masc.Pl
all. $3^{\text {rd }}$.Masc.Pl

Shlonsky's idea is that in going from (i) to (ii), the DP hasfarim moves from the complement of Q to Spec,QP thereby triggering Spec-Head agreement showing up on kol kul. But the number and gender marking on kol $\sim k u l$ bears no resemblance to agreement on nouns or adjectives (cf. zol 'cheap' / zolim 'cheapMasc-Pl, bul 'stamp' / bulim 'stamps-Masc-Pl') but is identical to the pronominal suffixes often found on nouns and prepositions (axot 'sister'/axotam 'their (Masc) sister'; beyn 'between'/ beynam 'between them-Masc'). Assuming one goes from (i) to (ii) via DP movement, the affix on kol appears to be a resumptive pronoun, a device often used in Hebrew.

${ }^{7}$ Sanchez(1996) posits the following constituent structure for the Spanish ladrona de joyas 'jewelry thief'

i. $\quad \mathrm{D}^{0}\left[\operatorname{PredP}_{\mathrm{NPP}}\right.$ ladrona $\left.{ }_{\mathrm{j}}\right] \operatorname{Pred}^{0}+\operatorname{Agr}^{0}{ }_{\mathrm{i}}$ de $\left[\operatorname{AgrP}[\mathrm{NP}\right.$ joyas $\left.] \mathrm{e}_{\mathrm{i}}\left[\mathrm{NP}_{\mathrm{j}}\right]\right]$

She comments "the element in Spec of AgrP is another NP. As the NP in this specifier position is strongly marked for agreement features in Spanish a dummy preposition $d e$ 'of' is used to avoid a clash in features."

${ }^{8}$ In (28) MON produces a meaning of type <et $>$. This assumes that the existential quantification of (27) comes from the outside. Remarks in footnote 4 suggest a higher type outcome for MON. Here's another reason to go in that direction. Hackl(2001) decomposes more than 3 students into a degree quantifier [-er than three] and an individual quantifier $M A N Y$ with the following semantics:

$$
[[M A N Y]]=\lambda \mathrm{d} \cdot \lambda \mathrm{f}_{<\mathrm{e}, \mathrm{t}>} . \lambda \mathrm{g}_{<\mathrm{e}, \mathrm{t}>} . \exists \mathrm{x} \text { st. } \mathrm{f}(\mathrm{x})=1 \& \mathrm{~g}(\mathrm{x})=1 \&|\mathrm{x}|=\mathrm{d}
$$


We get essentially this semantics for many if MON is adjusted to produce meanings of type $<<$ et $>,<<$ et $>, t>>$. Let me hint at how. The degree argument of many follows from it's status as a scalar adjective (see discussion of much and long above). The cardinality operator is a particular instantiation of $\mu$, proportional readings (Partee1988) would require further elaboration.

${ }^{9}$ But isn't lightness non-monotonic? Surely it is impossible that if $\mathrm{x}$ is part of $\mathrm{y}$ then $\mathrm{x}$ is less light than $\mathrm{y}$. That is true, but irrelevant. We are after the underlying property, in this case weight, on which the judgement is being made. In this respect, light is not different than heavy, both are based on a monotonic property. It does look like we're headed for a theory in which adjective meanings aren't themselves measure functions as in Bartsch and Vennemann (1973) and Kennedy (1997), rather they come to include measure functions. In other words, heavy gets to mean $\lambda \mathrm{x}[\operatorname{much}(\mathbf{w t}(\mathrm{x})]$ and light means $\lambda \mathrm{x}[\operatorname{little}(\mathbf{w t}(\mathrm{x})]$ (cf. Heim(2001) on short/tall).

${ }^{10}$ Ron Artstein(pc) suspects that in the heavy bottles the adjective heavy could have a collective reading if it is interpreted as a non-restrictive modifier. That would fit in with the rest of our story if non-restrictiveness meant it was positioned in Spec, AgrP.

\section{References}

Abney, S. (1989) “The English Noun Phrase in it's Sentential Aspect," MIT Phd. Adger, D. (1994) "Functional Heads and Interpretation," Phd thesis, Center for Cognitive Science, University of Edinburgh.

Barker, C. (1998) "Partitives, Double Genitives, and Anti-uniqueness," Natural Language and Linguistic Theory 16.4:679-717.

Bartsch, R. and T. Vennemann (1972) Semantic Structures: A Study in the Relation between Syntax and Semantics. Frankfurt: Athenäum Verlag.

Bhattacharya, T. (1999) "Specificity in the Bangla DP," in Rajendra Singh (ed.) Yearbook on South Asian Languages and Linguistics, vol 2, ed., SAGE Publications. New Delhi/London 71-99

Brisson, C. (1998) Distributivity, Maximality, and Floating Quantifiers, Phd dissertation, Rutgers University

Cartwright, H.M. (1975) "Amounts and Measures of Amounts," Noûs 9:143-164 [reprinted in F. Pelletier (ed) (1979) Mass Terms: Some Philosophical Problems Dordrecht Reidel]

Cinque, G. (1994) "On the evidence for partial N movement in the Romance DP," in Cinque, G, J. Koster, J.-Y. Pollock, L. Rizzi \& R. Zanuttini (eds.) Paths Towards Universal Grammar, Georgetown University Press, Georgetown. 85-110

Chierchia, G. (1998) "Plurality of Mass Nouns and The Notion of "Semantic Parameter," in S. Rothstein (ed.) Events and Grammar Kluwer 53-103

Delsing, L.O. (1993) The Internal Structure of Noun Phrases in the Scandinavian Languages. A Comparative Study. Phd dissertation, University of Lund. 
Díez, J.A. (1997) "A Hundred Years of Numbers. An Historical Introduction to Measurement Theory 1887-1990; Part I: The Formation Period. Two Lines of Research: Axiomatics and Real Morphisms, Scales and Invariance," Studies In History and Philosophy of Science Elsevier Science Ltd 28.1:167-185

Gawron, M. (2002) "Two Kinds of Determiner in DP," talk at LSA Winter Meeting

Giusti, G. (1991) "The Categorial Status of Quantified Nominals," Linguistiche Berichte 136: 438-452.

Giusti, G. (1997) "The Categorial Status Of Determiners," The New Comparative Syntax, L. Haegeman (ed.) 94-113. Cambridge: Cambridge University Press. [ P291.N48 1997]

Grimshaw, J. (1991) "Extended Projection," ms. Brandeis University

Grimshaw, J. (2000). "Extended projection and locality,” In Peter Coopmans, Martin Everaert, and Jane Grimshaw, (eds.), Lexical Specification and Insertion, John Benjamins. 115-133.

Hackl, M. (2001) "Comparative Quantifiers and Plural Predication," in K. Megerdoomian and L.A. Bar-el (eds.) WCCFL 20 Proceedings, Somerville, MA: Cascadilla Press. pp. 234-247.

Heim, I. (2001) "A Compositional Analysis of Scope-Splitting and lesscomparatives," handout for IRCS Colloquium at UPenn, 2 February 2001.

Higginbotham (1994): "Mass and Count Quantifiers," Linguistics \& Philosophy. 17(5):447-80

Jackendoff, R. (1977) X-Bar Syntax: A Study of Phrase Structure, Linguistic Inquiry Monograph Two, MIT Press.

Kennedy, C. (1997) Projecting the Adjective: The Syntax and Semantics of Gradability and Comparison. Ph.D. dissertation, University of California, Santa Cruz.

Kikuchi, A. (2001) “A Verb of Excess in Japanese," abstract from FAJL 3

(Formal Approaches to Japanese Linguistics) May 2001, MIT.

Klooster, W. G. (1972) The structure underlying measure phrase sentences Dordrecht, Reidel

Krifka, M. (1989): "Nominal Reference, Temporal Constitution and Quantification in Event Semantics," in Bartsch, R., van Benthem, J,. van Emde Boas, P. (eds): Semantics and Contextual Expressions, Dordrecht, Foris: $75-115$

Ladusaw, W.A. (1982) 'Semantic Constraints on the English Partitive Construction', Proceedings of WCCFL 1, Stanford, 231-242.

Lønning, J.T. (1987) "Mass Terms and Quantification," Linguistics and Philosophy 10:1-52.

Matthewson, L. (2001) "Quantification and the Nature of Crosslinguistic Variation," Natural Language Semantics 9(2):145-189

Nerbonne, J. (1995) "Nominal comparatives and generalized quantifiers," Journal of Logic, Language \& Information 4(4):273-300 
Parsons, T. (1970) “An Analysis of Mass and Amount Terms' Foundations of Language 6 362-388 [reprinted in F. Pelletier (ed) (1979) Mass Terms: Some Philosophical Problems Dordrecht Reidel]

Proudfoot A. and F. Cardo (1997) Modern Italian Grammar. A Practical Guide Routledge, London • New York

Partee, B. (1988) "Many Quantifiers," in Joyce Powers and Kenneth de Jong, (eds.), Proceedings of the 5th Eastern States Conference on Linguistics, Columbus: Ohio State University (1989), 383-402.

Rizzi, L. (1990) Relativized Minimality. Cambridge, Mass.: MIT Press.

Quine, W.V.O. (1960) Word and Object MIT Press.

Sanchez, L. (1996) Syntactic Structures In Nominals : A Comparative Study of Spanish and Southern Quechua, Phd dissertation, University of Southern California.

Schwarzschild R. \& K. Wilkinson (2002) "Quantifiers in Comparatives: A Semantics of Degree based on Intervals," Natural Language Semantics 10.1:1-41

Selkirk, E. (1977) "Some Remarks on Noun Phrase Structure," in P. Culicover, T. Wasow and A. Akmajian (eds.) Formal Syntax, Academic Press. 285-316

Shlonsky, U. (1991) "Quantifiers as functional heads: a study of quantifier float in Hebrew," Lingua 84:159-180

Smith, J. (1992) "Circumstantial complements and direct objects in the Romance languages: configuration, Case, and thematic structure." In I. Roca, ed., Thematic Structure: Its Role in Grammar, pp. 293--316. Dordrecht: Foris Publications.

Vos, R. (1999) A Grammar of Partitive Constructions, Ph.D. dissertation, Tilburg University.

Zamparelli, R. (1996) Layers in the Determiner Phrase, PhD dissertation, University of Rochester.

Zwarts, J. (1997) "Vectors as Relative Positions: A Compositional Semantics of Modified PPs. Journal of Semantics, 14:57-86. 